\title{
АНАЛИЗ ПРОБЛЕМ АДМИНИСТРИРОВАНИЯ НАЛОГА НА ПРИБЫЛЬ ОРГАНИЗАЦИЙ В УСЛОВИЯХ ФИНАНСОВОЙ НЕОПРЕДЕЛЕННОСТИ (НА МАТЕРИАЛАХ СТАВРОПОЛЬСКОГО КРАЯ)
}

\begin{abstract}
Аннотация. Целью исследования является выявление сложившихся тенденций, в том числе, незаконных, налогообложения прибыли организаций в Российской Федерации и выработка новых положений методологии фискализации последней. Налоговые поступления являются основой формирования доходной части бюджетов, в связи с чем, особый интерес вызывают вопросы оценки этих доходов, их пределов и возможности увеличения. Автором особое внимание уделяется способам администрирования налога на прибыль региональными налоговыми органами в современной экономической ситуации от региональных органов власти требуется решение проблемы активизации действующих и поиска дополнительных источников доходов бюджета, связанной с реализацией налоговой политики. В представленной статье выполнен анализ методического инструментария администрирования прибыли. Статистический метод применен в контексте изучения динамики поступления налога в бюджетную систему, сумм недоимок и задолженности. Выработаны концептуальные положения по оптимизации обложения прибыли как составного компонента методологии администрирования. Процесс формирования норм налогового законодательства выявил особую актуальность проблемы определения налога на прибыль и механизма его взыскания. Несомненна прямая зависимость государственного бюджета от налоговых поступлений в целом и поступлений от налога на прибыль в частности, в условиях формирования в России рыночных отношений. При этом существует ряд проблем в администрировании данного налога. Актуальными для изучения в данной области являются вопросы установления преференций на уровне субъекта Российской Федерации для повышения инвестиционной привлекательности региона.
\end{abstract}

Ключевые слова: налоговая система, налоговая политика, бюджет, прибыль, налоговая ставка, налоговая база, налоговая льгота, налоговый период, налоговые каникулы, платеж.

\begin{abstract}
The purpose of the present research is to define established tendencies (including illegal ones) in the process of taxation of corporate profits in the Russian Federation and to develop new methods of fiscalization of the latter. Tax revenues are the basis for establishing the revenue part of the budget. This creates special interest towards questions related to evaluation of these revenues, their limits and expansibility. In her research Roschupkina pays special attention to the means of the administration of profits tax by regional tax authorities. Today's economic situation demands regional authorities to activate effective and search for additional sources of budget revenues in relation to the implementation of tax policies. In this article the author has carried out analysis of the methodological instruments of profits administration. Roschupkina has applied the statistical research method to study dynamics of revenues coming into the budget system, amounts of arrears and debts. The author also develops the conceptual framework for improving the profits taxation as an element of administration methodology. The process of establishing tax legislation provisions has defined the significance of the problem of defining profits tax and mechanism of collecting it. It is quite obvious that there is a direct dependence of the state budget on tax revenues in general and profits tax in particular considering the conditions of the development of market relations in Russia. Meanwhile, there is a number of problems in the administration of the aforesaid tax. Thus, questions related to establishing preferences at the level of the Russian Federation constituent in order to increase the region's investment prospects come to the fore.
\end{abstract}

Keywords: tax holidays, tax period, tax benefit, tax base, tax rate, profit, budget, tax policy, tax system, payment. 


\section{Налоги и налогообложение 10(148) • 2016}

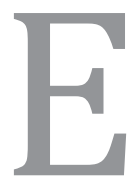

ж егод но Пра в и тельс т в о м Ставропольского края формируется и Думой региона принимается Закон, определяющий необходимый размер доходной части бюджета для исполнения функций, возложенных на законодательные и исполнительные органы края.

Фактическое поступление налога на прибыль организаций в бюджетную систему по территории Ставропольского края в 2015 году составило 11714,6 млн руб., при этом, поставленные параметры выполнены на 92,0\% и в бюджет не поступило 1014,2 млн руб. Необходимо отметить, что в ситуации невыполнения плановых значений по налогу на прибыль организаций, по факту, сложилась положительная динамика в сравнении с ситуацией 2014 года. Так, прирост поступлений в 2015 году в сравнении с 2014 годом составил 827,2 млн руб. или 7,6 \%.

В процессе исследования причин, которые оказали влияние на фактическое поступление налога на прибыль организаций, было установлено следующее.

Разумеется, на размер поступившего налога на прибыль организаций в бюджет Ставропольского края оказала влияние экономическая ситуация, которая сложилась в анализируемый период.

Отрицательным фактором, воздействовавшим на процесс выполнения установленного задания по поступлению налога на прибыль организаций выступило резкое (в 2,3 раза) увеличение суммы убытка, исчисленного организациями в процессе налогообложении, при этом, сумма убытка возросла на 5922,1 млн руб., и в 2015 году составила 10398,8 млн руб.

При этом, за счет роста рентабельности ряда организаций налогооблагаемая база для исчисления налога возросла на 28,1\% и составила 1932077 млн руб., что дало возможность обеспечить увеличение поступлений налога на прибыль организаций в сравнении с предыдущим налоговым периодом.

В бюджет Ставропольского края налог на прибыль организаций поступает от различных категорий налогоплательщиков, что также оказывает влияние на его формирование.

Так, в структуре поступлений налога за 2015 год более половины поступлений $(51,4 \%)$ прихо- дится на поступления от филиалов организаций, состоящих на учёте в других субъектах, 33,5\% от ставропольских организаций и 15,1\% от крупнейших налогоплательщиков, администрируемых Межрегиональными инспекциями по крупнейшим налогоплательщикам.

Основная доля прироста поступлений в сумме 1184,0 млн руб. обеспечена поступлениями филиалов иногородних компаний. Поступления от указанных плательщиков составили 6018,5 млн руб., что на 24,5\% или 1184,0 млн руб. больше, чем за 2014 год.

В общей сумме прироста налога 3,9\% или 32,5 млн руб. приходится на крупнейших налогоплательщиков, администрируемых Межрегиональными инспекциями по крупнейшим налогоплательщикам. Поступления от указанных плательщиков составили 1768,6 млн руб., что на 1,9\% или 32,5 млн руб. больше поступлений в 2014 году (1736,1 млн руб.).

Также возросли на 9\% до 3927,5 млн руб. и поступления от ставропольских организаций.

Отрицательную роль на формирование бюджета оказал значительный рост сумм возврата налога из краевого бюджета на банковские счета налогоплательщиков на основании представленных деклараций по прибыли с исчислением налога «к уменьшению» на общую сумму 819,5 млн руб., превышающую в 1,8 раза сумму возвратов за 2014 год.

При анализе результативности исполнения установленных параметров бюджета необходимо уделить внимание такому показателю, как наличие недоимки перед бюджетом у налогоплательщиков.

По данным статистической отчетности Федеральной налоговой службы по состоянию на 01.01.2016 недоимка по налогу на прибыль составила 160,5 млн руб., что является одним из резервов пополнения бюджета на предстоящий год.

При этом надо учитывать тот фактор, что 90\% такой задолженности имеют предприятия, признанные судом несостоятельными (банкротами), и перспектива поступления в бюджет налога на прибыль от указанных должников минимальна.

С учетом вышеизложенных факторов, в 2015 году показатели бюджета по налогу на 
прибыль организаций обеспечены лишь на 92,0 процента.

Рассматривая количество налогоплательщиков, которыми представлены налоговые декларации по налогу на прибыль, установлено резкое снижение их количества. На фоне снижения количества плательщиков налога на прибыльна 4,4\% снижено количество убыточных предприятий с 1509 до 1442 организации в 2016 году.

На протяжении двух лет при снижении количества организаций, фактически являющихся плательщиками налога на прибыль, наблюдается рост показателей, характеризующих экономическую ситуацию в регионе и, соответственно, положительная динамика поступления налога на прибыль в бюджет.

Таким образом, в 2015 году при росте доходов от реализации наблюдается снижение налоговой базы по прибыли на 28,2\%, или на 9035 млн руб.

На отрицательную динамику оказало влияние несколько факторов.

Во-первых, превышение роста расходов над доходами. Расчетное значение влияния указанного фактора составляет 530 млн руб. снижения налогооблагаемой базы, что соответствует 106 млн руб. налога.

Во-вторых, вступление в консолидированные группы налогоплательщиков трех высокорентабельных крупнейших организаций со значительной налоговой базой - 000 «Газпромтрансгаз Ставрополь», 000 «Ставролен» и 000 «РН-Ставропольнефтегаз». Налоговые декларации по прибыли данных организаций представляет ответственный участник консолидированной группы, и сведения о налогооблагаемой базе таких налогоплательщиков в отчете Ставропольского края отсутствуют, так как отражаются в налоговых органах по месту регистрации ответственного участника КГН (например, в городе Москве).

Для уплаты налога на прибыль организаций в бюджетную систему используется механизм, ранее предусмотренный для расчета доли прибыли обособленных подразделений, которую определяет ее ответственный участник. В первую очередь, устанавливается средняя арифметическая величина удельного веса среднесписочной численности работников (расходы на оплату труда) и удельный вес остаточной стоимости амортизируемого имущества участника (обособленного подразделения) в среднесписочной численности работников (расходах на оплату труда) и остаточной стоимости амортизируемого имущества в целом по группе.

Экономический эффект от создания консолидированной группы налогоплательщиков - снижение суммы платежей по налогу на прибыль организаций, так как участники группы суммируют и прибыли, и убытки от результатов деятельности каждого из участников, то есть, консолидируют налоговую базу.

В-третьих, в 2015 году для налогообложения организациями исчислены убытки в сумме 11559 млн руб., что превышает показатель 2014 года на 11,1\% или на 1160 млн руб. При этом удельный вес количества убыточных организаций по сравнению с показателем 2014 года $(12,7 \%)$ уменьшился на 1,3 процентных пункта и составил 11,4 процента.

Рассмотрим структуру поступлений налога наприбыль в бюджет Ставропольского края в 2015 году в разрезе категорий налогоплательщиков.

В структуре поступлений налога основную долю (34,3\%) составляют поступления от филиалов организаций, состоящих на учёте в других субъектах. Кроме того, поступления от ставропольских организаций составляют 25,5\%, от крупнейших налогоплательщиков, администрируемых Межрегиональными инспекциями по крупнейшим налогоплательщикам - 10,2 процента. С 2014 года появилась новая категория - участники консолидированных групп налогоплательщиков, на которую приходится $30,0 \%$ поступлений организаций и филиалов, осуществляющих деятельность на территории края, вошедших в консолидированные группы налогоплательщиков.

В суммовом выражении поступления налога по категориям налогоплательщиков выглядят следующим образом.

Поступления от филиалов иногородних компаний в сумме 4599 млн руб. на 1458 млн руб. или на 24,2\% ниже, чем в 2014 году. Поступления от организаций и филиалов, осуществляющих деятельность на территории края, не вошедших в консолидированные группы налогоплательщиков составили 4020,3 млн руб., что на 27,3\% 


\section{Налоги и налогообложение 10(148) • 2016}

или 861,7 млн руб. больше, чем в 2014 году трех организаций Ставропольского края, вступивших в КГН.

Поступления ставропольских организаций составили 3416,2 млн. руб., что на 507 млн руб. или на 13\% меньше поступлений 2014 года. Поступления крупнейших налогоплательщиков, администрируемых Межрегиональными инспекциями по крупнейшим налогоплательщикам снижено на 401 млн руб. или на $23 \%$ и составили 1374 млн руб..

В 2015 году сохраняется тенденция роста возвратов сумм налога на прибыль из краевого бюджета. В течение года организациям возвращено 1735,0 млн руб., что в 1,8 раза или на 748,0 млн руб., больше, чем в 2014 году (987,0 млн руб.), а также оказало влияние в указанном размере на исполнение установленных параметров.

Кроме этого, в результате неисполнения организациями обязанности своевременной уплаты налога на прибыль в краевой бюджет не поступило 201 млн руб., что соответствует размеру недоимки по налогу на прибыль в бюджет субъекта по состоянию на 01.01.2015.

Факторы, которые обеспечили выполнение установленных параметров, - это уплата налога на прибыль в краевой бюджет участниками консолидированных групп налогоплательщиков в части приходящейся доли. Данная сумма не прогнозировалась в связи с вновь вступившим законодательством о КГН, но участники КГН пополнили бюджет на 4 млрд руб.

На снижение поступлений от обособленных подразделений организаций, состоящих на учете в других субъектах Российской Федерации, и организаций, администрируемых межрегиональными инспекциями по крупнейшим налогоплательщикам, повлияли оба вышеназванных фактора.

Фактическое поступление налога на прибыль организаций в бюджет края за 2015 год составило 12230,4 млн руб., обеспечив исполнение бюджета на 109,2\%, дополнительно поступило 1027,9 млн руб.. Однако поступившая сумма на 1179,1 млн руб. или 8,8\% ниже, чем в 2014 году.

Экономические показатели Ставропольского края по данным Территориального органа Федеральной службы государственной статистики выглядят следующим образом.

В 2015 году сохраняется тенденция прошлых лет по снижению количества плательщиков налога на прибыль организаций. «Ненулевых» налоговых деклараций представлено 8007 организациями, что на 10\% меньше, чем в 2014 году. На 13\% сократилось число убыточных организаций (при расчете финансового показателя по данным налогового учета): с 1442 организаций в 2014 до 1255 в 2015 году.

таблица 1

\section{Динамика количества налогоплательщиков} налога на прибыль организаций

\begin{tabular}{|c|l|c|c|c|c|c|}
\hline $\begin{array}{c}\text { № } \\
\text { п/п }\end{array}$ & \multicolumn{1}{|c|}{ Наименование показателя } & $\begin{array}{c}\text { 2013, } \\
\text { шт. }\end{array}$ & $\begin{array}{c}\text { 2014, } \\
\text { шт. }\end{array}$ & $\begin{array}{c}\text { Динамика, } \\
\%\end{array}$ & $\begin{array}{c}\text { 2015, } \\
\text { шт. }\end{array}$ & $\begin{array}{c}\text { Динамика, } \\
\%\end{array}$ \\
\hline 1. & $\begin{array}{l}\text { Количество организаций, представивших } \\
\text { налоговые декларации по прибыли, в том } \\
\text { числе: }\end{array}$ & 11875 & 8903 & 74,9 & 8007 & 90 \\
\hline 2. & Заявивших прибыль & 10366 & 7461 & 72 & 6752 & 90,5 \\
\hline 3. & Заявивших убыток & 1509 & 1442 & 95,6 & 1255 & 87 \\
\hline 4. & $\begin{array}{l}\text { Общее количество юридических лиц, со- } \\
\text { стоящих на учете в Ставропольском крае }\end{array}$ & 44175 & 43559 & 98,6 & 44681 & 102,6 \\
\hline 5. & $\begin{array}{l}\text { Доля юридических лиц, плательщиков } \\
\text { налога на прибыль }\end{array}$ & 26,9 & 20,4 & 68,2 & 17,9 & 87,7 \\
\hline
\end{tabular}


Сократилась и доля плательщиков налогана прибыль в общем количестве юридических лиц с 20,4\% до 17,9 процента.

Таким образом, поступления налога на прибыль в бюджет обеспечили 6752 организации, состоящие на налоговом учете в Ставропольском крае, 3 организации, администрируемые межрегиональными инспекциями по крупнейшим налогоплательщикам, более 200 обособленных подразделений организаций, зарегистрированных за пределами Ставропольского края, а также участники 7 консолидированных групп налогоплательщиков.

Рассмотрим показатели статистического отчета формы №5-П, сформированного на основе данных налогового учета организаций, отраженных в налоговых декларациях за 2015 год.

В 2015 году роста расходов соответствует росту доходов, но налоговая база в сравнении с показателем 2014 года снизилась на 1713 млн руб. или на 7,4 процента.

На снижение налоговой базы повлияли несколько факторов, среди которых снижение количества организаций, получивших прибыль и представивших декларацию налогоплательщиков, на 709 организаций: с 7461 в 2014 до 6752 в 2015 году.
Значительное влияние на снижение налоговой базы по налогу на прибыль оказало отражение убытков, полученных в предыдущих периодах, в сумме 1151 млн руб., в результате чего бюджет потерял 230 млн руб.

В результате анализа эффективности выполнения плановых параметров бюджета по налогу на прибыль за 2013-2014 годы было установлено, что более 70\% поступлений обеспечили налогоплательщики, которые не зарегистрированы на территории края в качестве юридического лица. В 2015 году ситуация осталась прежней, однако изменились доли налога на прибыль, поступившие от конкретной категории плательщиков, в общей сумме поступившего в бюджет налога, а также по отношению друг к другу.

В структуре поступлений налога за 2015 год основная доля $(36,1 \%)$ приходится на суммы филиалов организаций, состоящих на учёте в других субъектах, кроме того:

- $\quad 27,9 \%$ - поступления организаций, вошедших в консолидированные группы налогоплательщиков;

- $\quad 26,9 \%$ - поступления ставропольских организаций;

- $\quad$ 9,1\% - поступления крупнейших налогоплательщиков, администрируемых межре-

таблица 2

\section{Анализ налоговой базы по налогу на прибыль организаций} (на материалах Ставропольского края)

\begin{tabular}{|c|c|c|c|c|c|}
\hline \multirow{2}{*}{$\begin{array}{c}\text { № } \\
\text { П/ா }\end{array}$} & \multirow{2}{*}{ Наименование показателя } & \multirow{2}{*}{$\begin{array}{c}2014, \\
\text { млн руб. }\end{array}$} & \multirow{2}{*}{$\begin{array}{c}2015, \\
\text { млн руб. }\end{array}$} & \multicolumn{2}{|c|}{ Отклонение } \\
\hline & & & & млн руб. & $\%$ \\
\hline 1. & Доходы от реализации & 631645 & 640239 & 8594 & 101,4 \\
\hline 2. & Внереализационные доходы & 20146 & 20436 & 310 & 101,5 \\
\hline 3. & $\begin{array}{l}\text { Расходы, уменьшающие сумму доходов } \\
\text { от реализации }\end{array}$ & 611297 & 620610 & 9313 & 101,5 \\
\hline 4. & Внереализационные расходы & 28555 & 30901 & 2346 & 108,2 \\
\hline 5. & Налоговая база для исчисления налога & 23042 & 21328 & -1717 & 92,6 \\
\hline 6. & $\begin{array}{l}\text { Сумма убытка организации, } \\
\text { исчисленного при налогообложении }\end{array}$ & 11770 & 12938 & 1168 & 110 \\
\hline
\end{tabular}




\section{Налоги и налогообложение 10(148) • 2016}

гиональными инспекциями по крупнейшим налогоплательщикам.

В абсолютном значении, поступления на налога на прибыль в бюджет от всех категорий плательщиков, снижены. А именно, поступления от филиалов иногородних компаний составили 4415 млн руб., что на 3,2\% или 145 млн руб. меньше, чем в 2014 году.

Поступления от организаций и филиалов, осуществляющих деятельность на территории края и вошедшим в консолидированные группы налогоплательщиков, составили 3412,0 млн руб., что на 15,2\% или 611 млн руб. меньше поступлений 2014 года.

От ставропольских организаций поступило в бюджет 3290 млн руб., что на 3,9\% или 130 млн руб. меньше, чем в 2014 году.

Поступления крупнейших налогоплательщиков, администрируемых межрегиональными инспекциями по крупнейшим налогоплательщи- кам, составили 1113 млн руб., что на 18,6\% или 250 млн руб. меньше, чем за 2014 год.

Следовательно, в 2015 году при снижении абсолютных показателей поступлений установленные параметры краевого бюджета по налогу на прибыль выполнены. Это стало возможным в результате того, что при планировании бюджета Ставропольского края была учтена возможность снижения уровня доходов по основным отраслям производства.

В каждом из анализируемых периодов выявлены различные причины, которые оказали как положительное, так и отрицательное влияние на формирование бюджета Ставропольского края, в отношении налога на прибыль организаций наиболее существенными из них предстают динамика экономической ситуации в регионе и изменение фискального законодательства в части консолидации плательщиков в группы.

\section{Исследование выполнено при финансовой поддержке РФФИ в рамках научного проекта №16-36-00077 мол_а}

\section{Библиография}

1. Малис, Н.И. Налоговая политика в противодействии теневой экономике: повышение собираемости налогов // Научно-исследовательский финансовый институт. Финансовый журнал. 2014. №1. С. 81-90.

2. Рощупкина, В.В. Показатель налоговой нагрузки как индикатор эффективности фискальных мер государства // Экономика. Налоги. Право. - Москва. - Финансовый университет, 2016. №2. C.134-141.

3. Рощупкина, В.В. Современные проблемы прогнозирования потенциала субъекта федерации по налогу на прибыль организаций с учетом крупнейших и консолидированных групп налогоплательщиков // Финансовая аналитика: проблемы и решения. - Москва, 2016. №12 (224). С.12-20.

4. Швандар К.В., Анисимова А.А. Фискальная консолидация: мировой опыт // Финансовая аналитика: проблемы и решения. - Москва, 2016. №28 (310) - С.51-62.

5. Alesina A., Carloni D., Lecce G. The Electoral Consequences of Large Fiscal Adjustments, NBER Working Paper. 2012. No. 17655.

6. Neaime S. Sustainability of budget deficits and public debts in selected European Union countries // The Journal of Economic Asymmetries. 2015. Vol. 12. Iss. 1. P. 1-21.

7. Официальный сайт Министерства финансов Российской Федерации [Электронный ресурс] // Режим доступа // http://www.minfin.ru

8. Официальный сайт Федеральной налоговой службы [Электронный ресурс] // Режим доступа // http:// www.nalog.ru

9. Официальный сайт Федеральной службы государственной статистики Российской Федерации [Электронный ресурс] // Режим доступа // http:// www.gks.ru 


\section{References (transliterated)}

1. Malis, N.I. Nalogovaya politika v protivodeistvii tenevoi ekonomike: povyshenie sobiraemosti nalogov // Nauchno-issledovatel’skii finansovyi institut. Finansovyi zhurnal. 2014. №1. S. 81-90.

2. Roshchupkina, V.V. Pokazatel' nalogovoi nagruzki kak indikator effektivnosti fiskal'nykh mer gosudarstva // Ekonomika. Nalogi. Pravo. - Moskva. - Finansovyi universitet, 2016. №2. C.134-141.

3. Roshchupkina, V.V. Sovremennye problemy prognozirovaniya potentsiala sub"ekta federatsii po nalogu na pribyl' organizatsii s uchetom krupneishikh i konsolidirovannykh grupp nalogoplatel'shchikov // Finansovaya analitika: problemy i resheniya. - Moskva, 2016. №12 (224). C.12-20.

4. Shvandar K.V., Anisimova A.A. Fiskal'naya konsolidatsiya: mirovoi opyt // Finansovaya analitika: problemy i resheniya. - Moskva, 2016. №28 (310) - C.51-62.

5. Alesina A., Carloni D., Lecce G. The Electoral Consequences of Large Fiscal Adjustments, NBER Working Paper. 2012. No. 17655.

6. Neaime S. Sustainability of budget deficits and public debts in selected European Union countries // The Journal of Economic Asymmetries. 2015. Vol. 12. Iss. 1. R. 1-21.

7. Ofitsial'nyi sait Ministerstva finansov Rossiiskoi Federatsii [Elektronnyi resurs] // Rezhim dostupa // http://www.minfin.ru

8. Ofitsial'nyi sait Federal'noi nalogovoi sluzhby [Elektronnyi resurs] // Rezhim dostupa // http:// www. nalog.ru

9. Ofitsial'nyi sait Federal'noi sluzhby gosudarstvennoi statistiki Rossiiskoi Federatsii [Elektronnyi resurs] // Rezhim dostupa // http:// www.gks.ru 